\title{
Inhibitory Activities of Zygophyllum album: A Natural Weight-Lowering Plant on Key Enzymes in High-Fat Diet-Fed Rats
}

\author{
Kais Mnafgui,, ${ }^{1,2}$ Khaled Hamden, ${ }^{1,3}$ Hichem Ben Salah, ${ }^{2}$ Mouna Kchaou, ${ }^{2}$ Mbarek Nasri, ${ }^{4}$ \\ Sadok Slama, ${ }^{4}$ Fatma Derbali, ${ }^{4}$ Noureddine Allouche, ${ }^{2}$ and Abdelfattah Elfeki ${ }^{1}$
}

${ }^{1}$ Laboratory of Animal Ecophysiology, Faculty of Sciences of Sfax, University of Sfax, P.O. Box 95, Sfax 3000, Tunisia

${ }^{2}$ Laboratory of Chemistry of Natural Products, Faculty of Sciences of Sfax, B.P. 1171, Sfax 3000, Tunisia

${ }^{3}$ Biotechnology High School of Sfax (ISBS), University of Sfax, P.O. Box 261, Sfax 3052, Tunisia

${ }^{4}$ Hematological and Clinical Biochemistry Laboratory, Hospital of Sidi Bouzid, Sidi Bouzid 9100, Tunisia

Correspondence should be addressed to Khaled Hamden, khaled.hamden@yahoo.fr

Received 13 May 2012; Accepted 13 August 2012

Academic Editor: David Mischoulon

Copyright () 2012 Kais Mnafgui et al. This is an open access article distributed under the Creative Commons Attribution License, which permits unrestricted use, distribution, and reproduction in any medium, provided the original work is properly cited.

\begin{abstract}
Obesity is a serious health problem that increased risk for many complications, including diabetes and cardiovascular disease. The results showed EZA, which found rich in flavonoids and phenolic compounds, exhibited an inhibitory activity on pancreatic lipase in vitro with $\mathrm{IC}_{50}$ of $91.07 \mu \mathrm{g} / \mathrm{mL}$. In vivo administration of this extract to HFD-rats lowered body weight and serum leptin level; and inhibited lipase activity of obese rats by $37 \%$ leading to notable decrease of T-Ch, TGs and LDL-c levels accompanied with an increase in HDL-c concentration in serum and liver of EZA treated HFD-rats. Moreover, the findings revealed that EZA helped to protect liver tissue from the appearance of fatty cysts. Interestingly, supplementation of EZA modulated key enzyme related to hypertension such as ACE by $36 \%$ in serum of HFD animals and improve some of serum electrolytes such as $\mathrm{Na}^{+}, \mathrm{K}^{+}$, $\mathrm{Cl}^{-}, \mathrm{Ca}^{2+}$ and $\mathrm{Mg}^{2+}$. Moreover, EZA significantly protected the liver-kidney function by reverted back near to normal the values of the liver-kidney dysfunction indices AST\&ALT, ALP, CPK and GGT activities, decreased T-Bili, creat, urea and uric acid rates. In conclusion, these results showed a strong antihypelipidemic effect of EZA which can delay the occurrence of dislipidemia and hypertension.
\end{abstract}

\section{Introduction}

Obesity is a serious health problem worldwide $[1,2]$. The prevalence of obesity is rising dramatically among all ages with the changes of lifestyles and dietary fat intake [3]. The accumulation of abnormal or excessive amount of body fat could have several health complications associated with major risk factor for several serious chronic diseases, such as type 2 diabetes, cardiovascular disease, hypertension, stroke, asthma, and certain forms of cancer [4-6]. In fact, higher levels of cholesterol in blood and dietary were considered a major risk factor for coronary heart diseases [7]. Though, lipid lowering could attenuate the progress of these various metabolic disorders and reduce morbidity and mortality [8]. The synthetic pharmacological drugs prescribed against hyperlipidemia and overweight had adverse side effects [9]. Thus, there is a potent need to explore complementary alternative medicine particularly from medicinal plants. One therapeutic approach of obesity and hyperlipidemia is to delay the digestion and absorption of fat via the use of safer lipase inhibitors from natural sources in order to reduce the postprandial hyperlipidemia [10]. Zygophyllum album is a shrubby plant belonging to Zygophyllaceae family [11] which includs about 27 genera and 285 species frequently restricted to arid and semiarid areas [12]. In fact, many plants belonging to this genus have anti-inflammatory, molluscicidal, and expectorant activities [13]. The main constituents described from Zygophyllum species are zygophyllin, quinovic acid, and glycosides, which have been demonstrated to have anti-inflammatory and antipyretic 
activity [14]. Furthermore, seven flavonoids together with two phenolic acids were isolated from Zygophyllum album $\mathrm{L}$ and identified as quercetin, quercetin-3,7-di$\mathrm{O}-\beta$-glucopyranoside, isorhamnetin-3-O- $\beta$-galactopyranoside, isorhamnetin-3-O- $\beta$-glucopyranoside and isorhamnetin-3-O- $\alpha$-rhamnopyranosyl-(1/6)-O- $\beta$-glucopyranoside (isorhamnetin-3-O-rutinoside), isorhamnetin-3-O- $\alpha$ rhamnopyranosyl-(1/6)-O- $\beta$-galactopyranoside (isorhamnetin 3-O-robinoside), isorhamnetin-3-O- $\beta$-glucopyranoside-7-O- $\alpha$-rhamnopyranoside, gentisic acid, and gentisic acid 5-O- $\alpha$-rhamnopyranoside [14-16]. In fact, Zygophyllum album is widespread in the deserts and salt marshes of southern Tunisia. The leaves, stems, and fruits of this plant are used in the Tunisian folk medicine as a drug active against rheumatism, gout, and asthma. It is also used as diuretic, local anaesthetic, antihistaminic, and antidiabetic agent [17]. Therefore, this investigation was aimed to report the therapeutic effect of Zygophyllum album against hyperlipidemia and hypertension induced with a standardized high fat-diet (HFD) in female rats along with possible mechanisms.

\section{Material and Methods}

2.1. Preparation of Ethanol Extract and Fractions. Zygophyllum album was collected from Douz (south of Tunisian) in July 2011. The taxonomic identification of the plant material was confirmed by Professor Mohamed Chaieb in the botany laboratory of the Faculty of Sciences, Sfax University, Tunisia. Air-dried and powdered leaves and flowers (800 g) of Zygophyllum album were macerated with $80 \%$ ethanol for $24 \mathrm{~h}$ three times at room temperature using a mechanical stirrer. The extract was filtered through filter paper and concentrated with a vacuum evaporator. The remaining aqueous solution was fractionated successively with hexane, ethyl acetate, and butanol to obtain the corresponding fractions: hexane $(2.7 \mathrm{~g})$, ethyl acetate $(69.0 \mathrm{~g})$, and butanol $(80.6 \mathrm{~g})$. On the other hand, a second extraction of powdered leaves and flowers $(450 \mathrm{~g})$ was performed in the same conditions with $99 \%$ ethanol. After filtration, the ethanol was evaporated under reduced pressure to yield the ethanolic extract $(45 \mathrm{~g})$.

2.2. Determination of Phenolic Content. The total phenolic content in extracts was determined with Folin-Ciocalteau reagent using the method of Chen et al. [18]. A standard curve must be first plotted using gallic acid as a standard. Different concentrations of gallic acid were prepared in methanol, and their absorbances were recorded at $750 \mathrm{~nm}$. $100 \mu \mathrm{L}$ of diluted sample was added to $2 \mathrm{~mL}$ of $2 \%$ $\mathrm{Na}_{2} \mathrm{CO}_{3}$ aqueous solution. After $2 \mathrm{~min}, 100 \mu \mathrm{L}$ of $50 \%$ FolinCiocalteau reagent was added. The final mixture was shaken and then incubated at room for $30 \mathrm{~min}$ in the dark at room temperature. The absorbance of all samples was measured at $750 \mathrm{~nm}$, and the results are expressed in $\mathrm{mg}$ gallic acid equivalents per gram extract (mg GAE/g extract).
2.3. Determination of Flavonoid Content. The total flavonoid content in extracts was determined according to Djeridane et al. [19], using a method based on the formation of a complex flavonoid aluminium, having the maximum absorbance at $430 \mathrm{~nm}$. Quercetin was used to make the calibration curve. About $1 \mathrm{~mL}$ of diluted sample was mixed with $1 \mathrm{~mL}$ of $2 \%$ aluminium trichloride $\left(\mathrm{AlCl}_{3}\right)$ methanolic solution. After incubation at room temperature for $15 \mathrm{~min}$, the absorbance of the reaction mixture was measured at $430 \mathrm{~nm}$ and the total flavonoid content was expressed in mg quercetin equivalents per gram of extract (mg QE/g extract).

2.4. Determination of Lipase Activity In Vitro. The method was modified from the assay reported by Nakai et al. [20], in which 4-methylumbelliferyl oleate (4-MU oleate) was used as a substrate to measure the pancreatic lipase inhibitory activity of all samples. Briefly, the assay was conducted by mixing the pancreatic lipase solution with 4-MU solution. The plate was immediately placed in the $37^{\circ} \mathrm{C}$ preheating $\mathrm{FL} \times 800$ micro plate fluorescence reader to measure the amount of 4-methylumbelliferone released by lipase every minute for $30 \mathrm{~min}$ at an excitation wavelength of $360 \mathrm{~nm}$ with a tolerance of $\pm 40 \mathrm{~nm}$ and an emission wavelength of $455 \mathrm{~nm}$ with a tolerance of $\pm 20 \mathrm{~nm}$. The lipase inhibitive activity was determined by measuring the effect on the enzyme reaction rate after adding extracts, compared with the control (fluvastin is used as positive control)

$$
\mathrm{PI}=\frac{\text { Absorbance }_{\text {control }}-\text { Absorbance }_{\text {test }}}{\text { Absorbance }_{\text {control }}} \times 100 .
$$

2.5. Animals and Treatments. The assays of the present study were conducted on adult female Wistar rats, weighting $140 \pm$ $10 \mathrm{~g}$, which were obtained from the local Central Pharmacy, Tunisia. All rats were kept in an environmentally controlled breeding room (temperature: $20 \pm 2^{\circ} \mathrm{C}$; humidity: $60 \pm 5 \%$; $12 \mathrm{~h}$ dark/light cycle) where they had standard diets and free access to tap water. The experimental protocols were conducted in accordance with the guide for the care and use of laboratory animals issued by the University of Sfax, Tunisia and approved by the Committee of Animal Ethics. The rats were randomly divided in four groups of eight animals each.

Group I: (control) normal female rats were fed with normal chow diet.

Group II: (HFD) female rats received high-fat diet (10\% sheep fat $+0.1 \%$ cholic acid $/ \mathrm{kg}$ chow diet) to induce hyperlipidemia for 6 weeks. The cholic acid is a bile acid involved to facilitate the formation of micelles, which promotes processing of dietary fat.

Group III: (fluv.) female rats received HFD and fluvastatin $(2 \mathrm{mg} / \mathrm{kg}$, body weight/daily) for 6 weeks. Fluvastatin (trade names Lescol, Canef, and Vastin) is a member of the drug class of statins, used to treat hypercholesterolemia and to prevent cardiovascular disease.

Group IV: (EZA) female rats received HFD and treated with ethanolic extract of Zygophyllum album by gastric gavage route food $(400 \mathrm{mg} / \mathrm{Kg}$ of body weight/daily) for 6 weeks. 
After the 6 weeks induction, the animals were sacrificed by decapitation in order to minimize the handling stress, and the trunk blood collected. The serum was prepared by centrifugation $\left(1500 \times \mathrm{g}, 15 \mathrm{~min}, 4^{\circ} \mathrm{C}\right)$, frozen, and stored at $-20^{\circ} \mathrm{C}$ until analysis. The kidney and liver were removed and cleaned of fat. All samples were stored at $-80^{\circ} \mathrm{C}$ until used. For histological studies, pieces of liver were fixed in a Bouin solution for $24 \mathrm{~h}$ and then embedded in paraffin. Sections of $5-\mu \mathrm{m}$ thickness were stained with hematoxylin eosin. The slides were photographed with an Olympus UTU1X-2 camera connected to an Olympus CX41 microscope (Tokyo, Japan).

2.6. Biochemical Analysis. The animals were sacrificed by decapitation and the trunk blood collected. The serum was prepared by centrifugation $\left(1500 \times \mathrm{g}, 15 \mathrm{~min}, 4^{\circ} \mathrm{C}\right)$ and stored at $-80^{\circ} \mathrm{C}$ until biochemical analysis. The liver of each rat was excised and homogenized in Tris-Buffered Saline (TBS), pH 7.6 and centrifuged $(5000 \times \mathrm{g}, 20 \mathrm{~min})$. The supernatant of liver homogenate was frozen and stored for further use in the profile lipid assay. Serum leptin levels were determined by a commercially available EnzymeImmunoassay (Alpco Diagnostics, Salem NH) which utilizes two specific polyclonal antibodies for mouse and rat leptin. The analyses of serum lipase and serum lipids level of triglycerides (TGs), total cholesterol (T-Ch), high density lipoprotein cholesterol (HDL-c), low density lipoprotein cholesterol (LDL-c) were measured using the corresponding commercial kits (Biolabo, France) on an automatic biochemistry analyzer (BS 300, China) at the pathological laboratory of Sidi Bouzid Hospital. Serum LDL-cholesterol concentration was determined according to formula [21]: $\mathrm{LDL}_{\text {cholesterol }}=$ total cholesterol-(triglycerides/5)- $\mathrm{HDL}_{\text {cholesterol }}$. The serum activity of Angiotensin converting enzyme (ACE) was measured using commercial kit (Trinity Biotech, UK). Serum electrolytes concentrations were determined by an automatic ion analyzer (IA 300, Japan). Serum levels of Creatine phosphokinase (CPK), aspartate aminotransferase (AST), alanine aminotransferase (ALT), alkaline phosphatase (ALP), gamma-glutamyl transpeptidase (GGT) and total bilirubin (T-Bili) activities and creatinine, uric acid, and urea rates were measured in frozen aliquots of serum by standardized enzymatic procedures using commercial kits from (Biolabo, France) on an automatic biochemistry analyzer (Vitalab Flexor E, USA) at the clinic pathological laboratory of Sidi Bouzid Hospital.

2.7. Statistical Analysis. Data are presented as means \pm standard deviation (SD). Statistical significance was assessed by the Fisher test. ${ }^{*} P<0.05$ was considered statistically significant.

\section{Results}

3.1. Total Phenolics (TPs) and Total Flavonoids (TFs). The level of flavonoid and phenolic compounds in different extracts of Zygophyllum album is shown in Table 1. Except the hexane extract, which contained low amounts of
TABLE 1: Flavonoid and total phenolic contents of various extracts of Zygophyllum album.

\begin{tabular}{lcc}
\hline Sample & $\begin{array}{c}\text { Total flavonoid content } \\
(\mathrm{mg} \text { QE/g extract })\end{array}$ & $\begin{array}{c}\text { Total phenolic content } \\
\text { (mg GAE/g extract })\end{array}$ \\
\hline $\begin{array}{l}\text { Hexane fraction } \\
\begin{array}{l}\text { Ethyl acetate } \\
\text { fraction }\end{array}\end{array}$ & $21.8 \pm 0.11$ & $78.022 \pm 1.56$ \\
$\begin{array}{l}\text { Butanol fraction } \\
\text { Ethanolic } \\
\text { extract }\end{array}$ & $45.8 \pm 0.23$ & $394.28 \pm 7.88$ \\
\hline
\end{tabular}

TABLE 2: In vitro pancreatic lipase inhibition assay of various extract of Zygophyllum album.

\begin{tabular}{lccc}
\hline Sample & $\begin{array}{c}\text { Concentration } \\
(\mu \mathrm{g} / \mathrm{mL})\end{array}$ & $\%$ inhibition & $\mathrm{IC}_{50}(\mu \mathrm{g} / \mathrm{mL})$ \\
\hline \multirow{2}{*}{ Fluvastatin } & 25 & $74.58 \pm 1.13$ & \\
& 50 & $86.78 \pm 1.27$ & 16.76 \\
Hexane extract & 50 & $33.43 \pm 1.11$ & \\
& 100 & $48.52 \pm 1.42$ & 103.05 \\
Ethyl & 200 & $59.85 \pm 1.08$ & \\
acetate & 50 & $36.88 \pm 1.45$ & \\
& 100 & $46.23 \pm 1.07$ & 108.15 \\
Butanol & 200 & $59.3 \pm 1.03$ & \\
Extract & 50 & $37.83 \pm 2.02$ & \\
& 100 & $52.79 \pm 1.08$ & 94.71 \\
\hline & 200 & $68.86 \pm 1.36$ & \\
Ethanol extract & 50 & $44.03 \pm 1.41$ & \\
& 100 & $54.86 \pm 1.28$ & 91.07 \\
\hline
\end{tabular}

The data are expressed in mean \pm S.E.M. $n=3$ in each group.

flavonoid and polyphenol, the other extracts were found to be rich in these compounds. As shown in Table 1, the butanol extract showed the highest amount of phenolic compounds (403.46 mg GAE/g) followed by ethyl acetate $(394.28 \mathrm{mg}$ GAE/g) and ethanol (391.65 mg GAE/g) extracts.

3.2. Pancreatic Lipase Inhibitory Activity Assay In Vitro. As shown in Table 2, for the different solvent extract fractions, the $\mathrm{IC}_{50}$ values of ethanol and butanol extracts were $(91.07 \mu \mathrm{g} / \mathrm{mL}$ and $94.71 \mu \mathrm{g} / \mathrm{mL})$, respectively, indicating their strong inhibitory activity over other solvent extract fractions against the pancreatic lipase. It should be noted that fluvastatin showed potent inhibition of pancreatic lipase with a strong $\mathrm{IC}_{50}=16.76 \mu \mathrm{g} / \mathrm{mL}$. The potential inhibitory effects of ethanol extract via other extracts explain the use of this extract for the in vivo study.

3.3. Effect of EZA on Body Weight of HFD-Fed Female Rats. By the end of the 6 weeks, the body weight in each group of rats was measured. Also, HFD-fed animals presented significant 


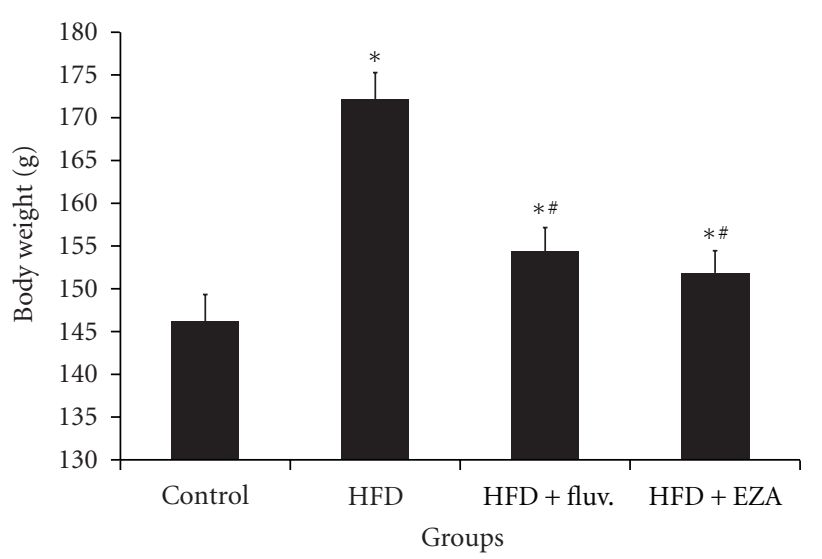

FIGURE 1: Effect of EZA on body weight of control and HFD treated rats. Values are given as mean \pm SD for group of 8 animals each. Values are statistically presented as follows: ${ }^{*} P<0.05$ significant differences compared to controls. ${ }^{\#} P<0.05$ significant differences compared to HFD rats.

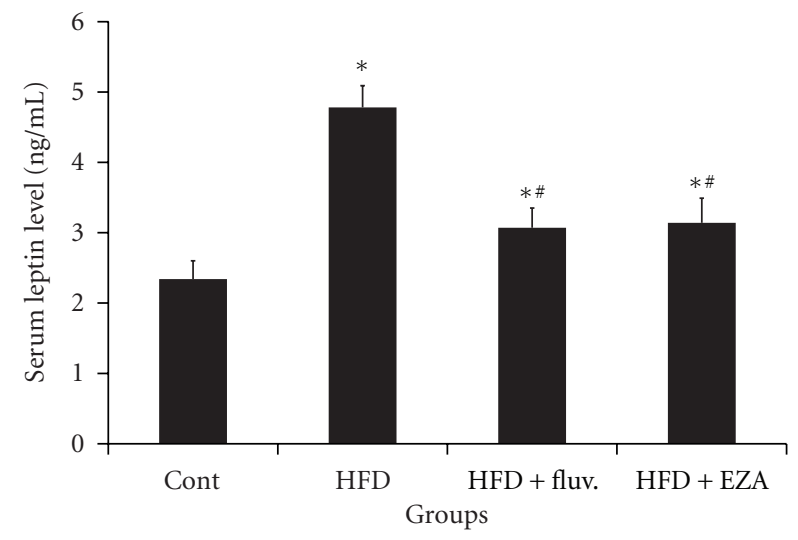

Figure 2: Effect of EZA on leptin level of experimental rats. Values are given as mean \pm SD for group of 8 animals each. Values are statistically presented as follows: ${ }^{*} P<0.05$ significant differences compared to controls. ${ }^{\#} P<0.05$ significant differences compared to HFD rats.

increase in body by $18 \%$ as compared to the control group. However, administration of EZA or fluvastatin to HFD-fed rats reduced significantly the body weight in comparison with the corresponding HFD group by (12 and 10\%), respectively, $P<0.05$ (Figure 1).

3.4. Effect of EZA on Serum Leptin Level of Experiment Animals. Serum leptin level was significantly increased in HFD group by $104 \%$ as compared to control animals. However, in response to the fluvastatin and EZA, serum leptin levels in groups received high-fat diet were significantly reduced by 35 and $34 \%$, respectively, as compared to HFD-fed rats, $P<0.05$ (Figure 2).

3.5. Effect of EZA on Lipase Activity and Lipids Profile in Serum and Liver. Figure 3 indicated that the lipase activity in serum of HFD-fed animals underwent a potent increase

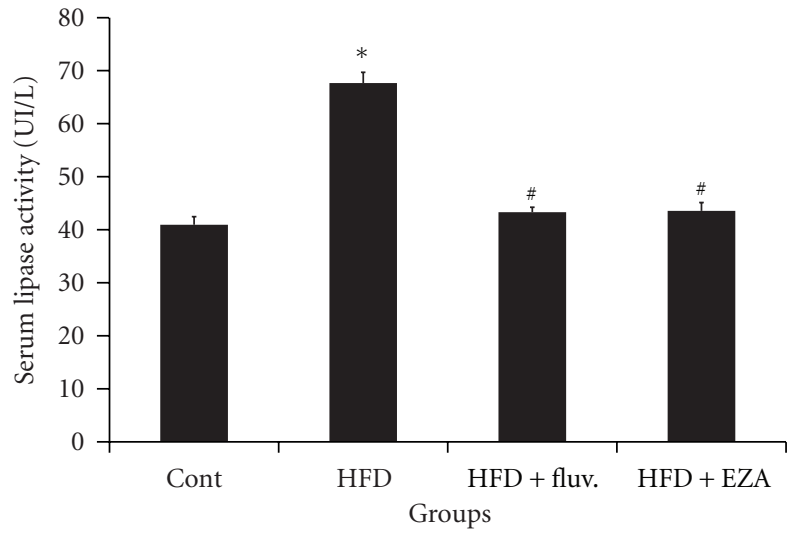

FIGURE 3: Effect of EZA on lipase activity in serum of control and HFD rats. Values are given as mean \pm SD for groups of 8 animals each. Values are statistically presented as follows: ${ }^{*} P<0.05$ significant differences compared to controls. ${ }^{\#} P<0.05$ significant differences compared to HFD rats.

of $65 \%$, as compared to control animals. The rise in lipase activity stimulates lipid absorption and, consequently, led to a remarkable increase in the TC, TG, and LDL-c levels in the serum by 62,45 , and $241 \%$, respectively, and in the liver by 127,130 , and $320 \%$, respectively, associated with significant decrease in the HDL-c level in serum and liver by 18 and $28 \%$, respectively, as compared to the normal female rats. However, the administration of EZA to the obese animals reverted back the lipase activity in serum by $37 \%$, which lowered the rate of TC, TG, and LDL-c and increased HDLc levels in serum and liver (Table 3). Moreover, fluvastatin supplementation to HFD-fed female rats was observed to improve their lipid profile.

3.6. Histopathological Studies of Liver in the Control and Experimental Groups of Rats. As shown in Figure 4, the section of the liver from a control rat showed a normal architecture. However, liver of HFD rat exhibited fatty cysts apparition in liver tissues, whereas, examination of liver tissue of HFD-fed rats treated with fluvastatin or EZA revealed potential protective action evidenced by reducing the development of fat cells in liver.

3.7. Effect of EZA on Serum ACE Activity. Figure 5 evidenced that the ACE activity in the serum of HFD-fed rats underwent a potent increase of $81 \%$ as compared to the control rats. However, the administration of the EZA or fluvastatin to the HFD rats was reverted back the activity of ACE in serum back by 36 and $34 \%$, respectively.

3.8. Effect of EZA on Serum Major Electrolytes. The findings indicated that compared to the control animals, there were significant reductions in serum $\mathrm{Na}^{+}, \mathrm{Cl}^{-}, \mathrm{Mg}^{2+}$ and $\mathrm{Ca}^{2+}$ by $7,9,30$, and $22 \%$, respectively, with an increase in the level of $\mathrm{K}^{+}$by $25 \%(P<0.05)$, observed in the serum of HFD-fed rats. However, administration of EZA to obese rats 
TABLE 3: Total cholesterol (T-Ch), LDL cholesterol (LDL-c), HDL cholesterol (HDL-c); and triglycerides (TGs) in serum and liver of HFDfed rats treated with EZA.

\begin{tabular}{|c|c|c|c|c|}
\hline Groups & Control & HFD & HFD + fluv. & HFD + EZA \\
\hline \multicolumn{5}{|c|}{ Serum $(\mathrm{mmol} / \mathrm{L})$} \\
\hline $\mathrm{T}-\mathrm{Ch}$ & $1.67 \pm 0.20$ & $2.72 \pm 0.14^{*}$ & $1.77 \pm 0.1^{* \#}$ & $1.74 \pm 0.1^{* \#}$ \\
\hline TGs & $0.96 \pm 0.21$ & $1.4 \pm 0.16^{*}$ & $0.96 \pm 0.07^{* \#}$ & $0.96 \pm 0.04^{* \#}$ \\
\hline LDL-c & $0.47 \pm 0.22$ & $1.61 \pm 0.16^{*}$ & $0.49 \pm 0.15^{* \#}$ & $0.53 \pm 0.03^{* \#}$ \\
\hline HDL-c & $1.02 \pm 0.09$ & $0.82 \pm 0.04^{*}$ & $1.04 \pm 0.07^{\#}$ & $1.05 \pm 0.06^{\#}$ \\
\hline \multicolumn{5}{|c|}{ Liver (mg/100 mg WT) } \\
\hline $\mathrm{T}-\mathrm{Ch}$ & $1.08 \pm 0.05$ & $2.45 \pm 0.15^{*}$ & $1.22 \pm 0.02^{* \#}$ & $1.27 \pm 0.05^{* \#}$ \\
\hline TGs & $0.63 \pm 0.07$ & $1.45 \pm 0.11^{*}$ & $0.72 \pm 0.06^{* \#}$ & $0.77 \pm 0.04^{* \#}$ \\
\hline LDL-c & $0.53 \pm 0.03$ & $1.78 \pm 0.12^{*}$ & $0.45 \pm 0.04^{* \#}$ & $0.48 \pm 0.03$ *\# \\
\hline HDL-c & $0.44 \pm 0.02$ & $0.38 \pm 0.01^{*}$ & $0.49 \pm 0.02^{* \#}$ & $0.51 \pm 0.02^{* \#}$ \\
\hline
\end{tabular}

WT: wet tissue. Values are given as mean \pm SD for groups of 8 animals each. Values are statistically presented as follows: ${ }^{*} P<0.05$ significant differences compared to controls. ${ }^{P} P<0.05$ significant differences compared to HFD rats.

reverted back near to normal value of the studied electrolytes (Table 4).

3.9. Effect of EZA on Liver-Kidney Function in HFD-Fed Female Rats. Table 5 demonstrated that the HFD-fed rats undertook an increase in terms of the AST, ALT, ALP, CPK, T-Bili, and GGT rates by $82,50,123,42,51$, and $96 \%$, respectively, and creatinine, urea, and uric acid rates in serum by 29,16 , and $20 \%$, respectively, when compared to control rats. Interestingly, the administration of EZA to obese rats seems to have reversed this increase back and ameliorated all indices related to liver and kidney dysfunction induced by high fat-diet.

\section{Discussion}

Obesity is defined as an increase of adipose tissue mass in the body and its accumulation in peripheral organs that leads to metabolic abnormalities such as diabetes mellitus, insulin resistance, and hyperlipidemia $[21,22]$. Obesity is thus a worldwide healthcare problem increasing morbid-mortality [22]. Actually, consumption of high-fat diets (HFDs) is a central risk factor for metabolic disorders linked to obesity [23]. Adverse effects of HFD on metabolic homeostasis such as dyslipidemia, diabetes mellitus, and cardiovascular diseases, for example, hypertension and coronary heart disease are linked to adipose tissue physiology and are highly influenced by gender [22-24]. In addition, the use of complementary treatments such as herbal remedies has been considered to have huge potential as an information source and starting point for the development of antiobesity products [25, 26]. Zygophyllum album is a deserted plant which belongs to Zygophyllaceae family, widely distributed in southern Tunisia and still used for treatment of diabetes, dermatitis, spasms, and dysmenorrhoea [27]. This study investigated that only EZA potentially inhibited lipase activity with $\mathrm{IC}_{50}=91 \mu \mathrm{g} / \mathrm{mL}$. This inhibitory action of EZA against lipase activity was related to the presence polyphenols and flavonoid compounds in EZA (Table 2). This investigation was in agreement with previous data reporting that alcohol extract of Zygophyllum album contains various flavonoid substances such as quercitin-3-O-rutinoside, isorhamnetin3-O-rutinoside, quinovic acid, kaempherol, Zygophyllin, $\beta$ sistosterol- $\beta$-D-glucopyranoside, Carbohydrates, and tannins [13-16]. Previous data reported that the presence of many flavonoids and polyphenol chemical structures was required for the enhancement of pancreatic lipase inhibition $[28,29]$. The flavonoid profiles of Zygophyllum album and Zygophyllum decumbens are very similar whereas that of Zygophyllum simplex is quite different. Flavonol 3-Orutinosides were only present in $Z$. album and $Z$. decumbens and not in $Z$. simplex. However, flavonol 3,7-diglycosides are synthesized by $Z$. simplex and also absent from two other species [30]. In vivo, the study revealed that EZA potentially inhibited lipase activity in serum. In fact, the main function of bile acid is to facilitate the formation of micelles, which promotes processing of dietary fat digestion by pancreatic lipase [31]. Thus, the pancreatic lipase is secreted from the pancreas, transported to small intestine, and hydrolyzes triglycerides nonabsorbable into absorbable monoglycerides and free fatty acids absorbable by small intestine [32]. It is well known that dietary fat is not directly absorbed from the intestine unless it has been subjected to the action of pancreatic lipase [33]. The application of pancreatic lipase inhibitor was examined as a treatment for diet-induced obesity in humans. It has been clinically reported that a pancreatic lipase inhibitor such as orlistat prevented obesity and hyperlipidemia through the increment of fat excretion into feces and the inhibition of pancreatic lipase [34]. In this study, the inhibition action of EZA on pancreas lipase activity inhibited the hydrolysis of dietary triglycerides nonabsorbable in the intestine into monoglycerides and free fatty acids absorbable by the intestine. This inhibitory action of lipase activity leads to decrease in T-Ch, LDL$c$ and TGs levels in both plasma and liver, consequently inhibition of lipid accumulation in liver and other tissues such as muscle consequently decrease in body weight as antiobesity action [35]. This increase of lipid accumulation in various tissues of high-fat diet rats is associated with elevated leptin level [36]. This result in accordance with 


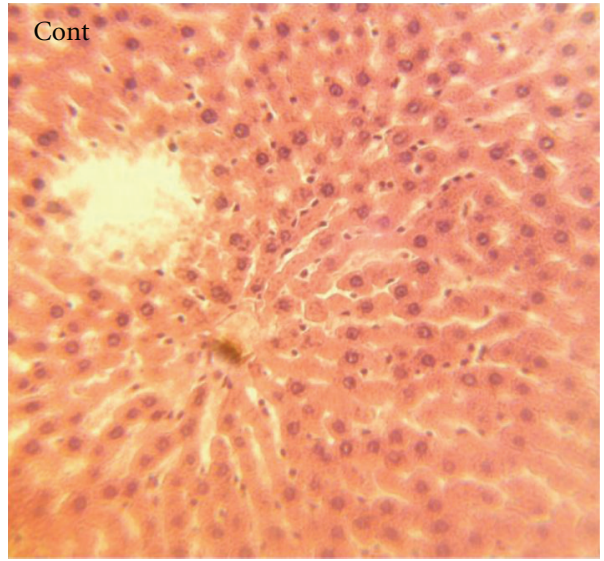

(a)

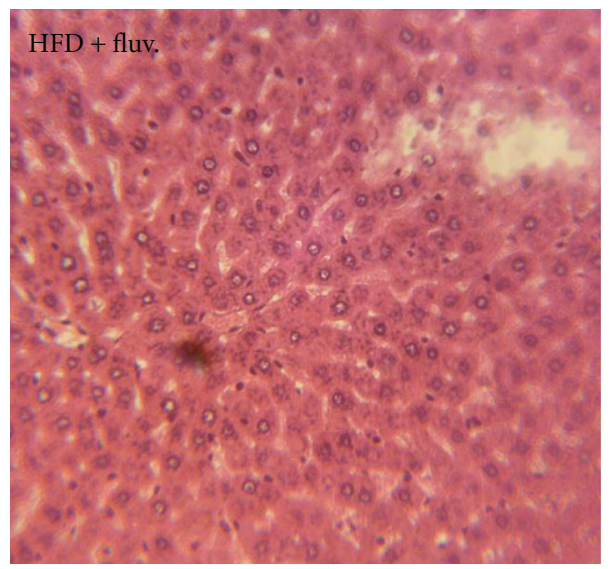

(c)

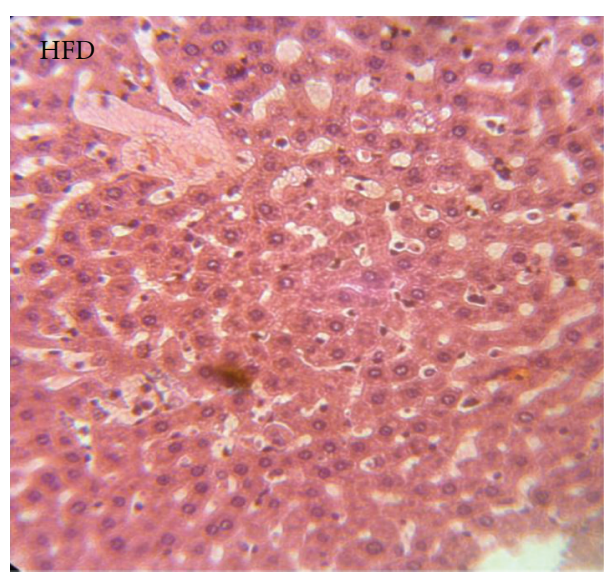

(b)

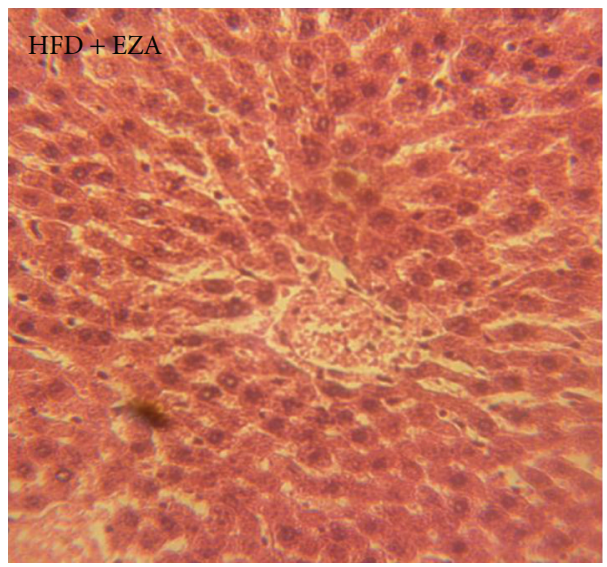

(d)

FIGURE 4: Histopathological studies of liver in the control and experimental groups of rats. The section of the liver from a control rat showing normal architecture; liver of HFD rats showing fatty cysts apparition in liver tissues; the liver of HFD rat treated with fluvastatin or EZA; a potential protective action was shown.

TABLE 4: Serum electrolytes levels of control animals and HFD-fed rats. Values are given as mean \pm SD for groups of 8 animals each.

\begin{tabular}{lcccc}
\hline Electrolytes & Control & HFD & HFD + fluv. & HFD + EZA \\
\hline $\mathrm{Na}^{+}(\mathrm{mmol} / \mathrm{L})$ & $138.85 \pm 0.75$ & $129.8 \pm 2.46^{*}$ & $134.85 \pm 1.01^{* \#}$ & $137.92 \pm 0.92^{\# @}$ \\
$\mathrm{~K}^{+}(\mathrm{mmol} / \mathrm{L})$ & $4.38 \pm 0.19$ & $5.48 \pm 0.12^{*}$ & $4.8 \pm 0.13^{* \#}$ & $4.42 \pm 0.18^{\# @}$ \\
$\mathrm{Ca}^{2+}(\mathrm{mmol} / \mathrm{L})$ & $2.86 \pm 0.07$ & $2.23 \pm 0.07^{*}$ & $2.52 \pm 0.07^{* \#}$ & $2.83 \pm 0.03^{\# @}$ \\
$\mathrm{Mg}^{2+}(\mathrm{mmol} / \mathrm{L})$ & $1.16 \pm 0.08$ & $0.81 \pm 0.05^{*}$ & $0.98 \pm 0.03^{* \#}$ & $1.2 \pm 0.06^{\#}$ \\
$\mathrm{Cl}^{-}(\mathrm{mmol} / \mathrm{L})$ & $111.15 \pm 1.61$ & $101.8 \pm 1.67^{*}$ & $108.72 \pm 0.85^{* \#}$ & $110.02 \pm 1.76^{\#}$ \\
\hline
\end{tabular}

WT: wet tissue. Values are statistically presented as follows: ${ }^{*} P<0.05$ significant differences compared to controls. ${ }^{\#} P<0.05$ significant differences compared to HFD rats ${ }^{\circledR} P<0.05$ significant differences to HFD rats treated with fluvastatin.

the study of Wang et al. [37], reported that leptin level is directly correlated to adipocyte lipid accumulation and hence, circulating leptin level is an ideal indicator of assessing obesity in both experimental animals and humans [38]. The positive effect of EZA on obesity and hyperlipidemia in both serum and liver was confirmed by a significant decrease of serum leptin level as compared to HFD rats. Moreover, the decrease of leptin level in serum of rats treated with EZA can prevent many other disorders related to obesity and hyperlipidemia such as hypertension. In fact, several previous studies revealed a strong correlation between serum leptin levels and body fat mass, suggesting that there is a leptin-resistant mechanism in obesity $[39,40]$. In addition, to regulate body fat mass, leptin also have multiple complex actions on cardiovascular and renal systems, such as sympathetic activation, increased insulin sensitivity, and renal sodium and water excretion [41]. Chronic effects of leptin increased arterial pressure despite a decrease in food intake. The rise of heart rate and renal vascular resistance were also noted and explained the consistent sympathetic activation 
TABLE 5: Liver profile indices (AST, ALT, ALP, GGT, CPK, and T-Bili) and kidney parameters (creatinine, urea, and uric acid) of control and experimental groups of rats. Values are given as mean \pm SD for groups of 8 animals each.

\begin{tabular}{|c|c|c|c|c|}
\hline & Control & HFD & HFD + fluv. & HFD + EZA \\
\hline \multicolumn{5}{|c|}{ Liver function } \\
\hline $\operatorname{AST}(\mathrm{UI} / \mathrm{L})$ & $106.7 \pm 11.52$ & $194.42 \pm 7.63^{*}$ & $128 \pm 6.54^{* \#}$ & $123 \pm 4.37^{* \#}$ \\
\hline $\operatorname{ALT}(\mathrm{UI} / \mathrm{L})$ & $60.57 \pm 8.88$ & $90.85 \pm 5.75^{*}$ & $71 \pm 9.14^{* \#}$ & $66.28 \pm 5.4^{\#}$ \\
\hline PAL (UI/L) & $281.28 \pm 42.8$ & $627.42 \pm 83.73^{*}$ & $365.28 \pm 78.39^{* \#}$ & $308.28 \pm 61.54^{\#}$ \\
\hline GGT (UI/L) & $3.42 \pm 0.53$ & $6.71 \pm 0.75^{*}$ & $4.57 \pm 0.74^{* \#}$ & $4.5 \pm 1.04^{* \#}$ \\
\hline CPK (UI/L) & $3128 \pm 193$ & $4147 \pm 198^{*}$ & $3317 \pm 185^{\#}$ & $3439 \pm 170^{* \#}$ \\
\hline T-Bili $(\mu \mathrm{mol} / \mathrm{L})$ & $1.66 \pm 0.21$ & $2.51 \pm 0.24^{*}$ & $1.6 \pm 0.33^{\#}$ & $1.64 \pm 0.26^{\#}$ \\
\hline \multicolumn{5}{|c|}{ Kidney function } \\
\hline Urea (mmol/L) & $6.35 \pm 0.41$ & $8.47 \pm 0.27^{*}$ & $6.41 \pm 0.37^{\#}$ & $6.79 \pm 0.47^{\#}$ \\
\hline Uric acid $(\mu \mathrm{mol} / \mathrm{L})$ & $62.73 \pm 6.74$ & $72.85 \pm 6.6^{*}$ & $64.77 \pm 7.46^{\#}$ & $62.37 \pm 5.14^{\#}$ \\
\hline Creatinine $(\mu \mathrm{mol} / \mathrm{L})$ & $44.7 \pm 0.94$ & $64.38 \pm 3.56^{*}$ & $41.3 \pm 1.7^{\#}$ & $46.4 \pm 1.88^{\#}$ \\
\hline
\end{tabular}

Values are statistically presented as follows: ${ }^{*} P<0.05$ significant differences compared to controls. ${ }^{*} P<0.05$ significant differences compared to HFD rats.

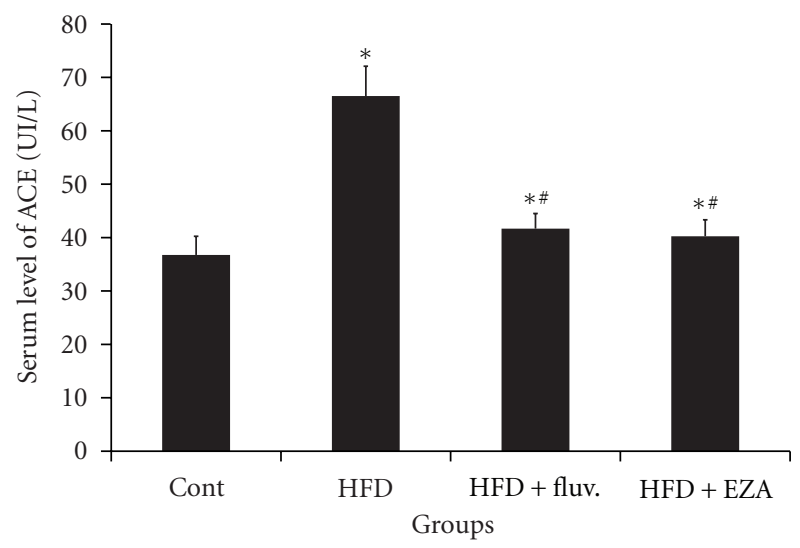

FIgURE 5: Effect of EZA on serum ACE activity of experimental rats. Values are given as mean \pm SD for group of 8 animals each. Values are statistically presented as follows: ${ }^{*} P<0.05$ significant differences compared to controls. ${ }^{\#} P<0.05$ significant differences compared to HFD rats.

by leptin [42]. Our findings showed that HFD-fed rats exhibited a potent increase in serum leptin associated with a significant rise in angiotensin converting enzyme activity (ACE), key enzyme related to hypertension. Hence, obesity is wide associated with the overexpression of ACE [43-45]. Interestingly, our study revealed that EZA modulated ACE activity in serum of HFD-fed rats. Actually, in the treatment of hypertension, inhibition of the angiotensin converting enzyme is established as a one modem therapeutic principle. Other major drugs to treat hypertension are $\beta$-receptor blockers and calcium antagonists. Further, supplementation of EZA improves some of serum electrolytes involved in blood pressure and obesity homeostasis such as $\mathrm{Na}^{+}, \mathrm{K}^{+}$, $\mathrm{Cl}^{-}, \mathrm{Ca}^{2+}$, and $\mathrm{Mg}^{2+}$. This result in accordance with previous observations that high dietary Calcium and Magnesium both with and without dairy reduce WAT inflammatory gene expression was confounded by $\mathrm{Ca} /$ dairy-associated reductions in body weight and adiposity [46, 47]. They proved remarkably efficient in the decrease of liver and kidney dysfunction indices in HFD-fed rats, namely, the AST, ALT, ALP, CPK, T-Bili, and GGT rates and the urea and creatinine levels. The strong therapeutic effect and potential of EZA are presumably associated with its potent antiobesity and hypolipidemic properties.

\section{Conclusion}

The results demonstrated a strong antihypelipidemic effect of EZA which can delay the occurrence of dislipidemia and hypertension complications. Thus, this study provides the possible pharmacologic rationale to the medicinal use of Zygophyllum album in the development of antiobesity drugs.

\section{Conflict of Interests}

The authors declare that they have no conflict of interests.

\section{Acknowledgments}

The authors gratefully acknowledge the Ministry of Higher Education, Scientific Research and Technology in Tunisia for financial support. The authors wish to express their sincere gratitude to Dr. Zaeir Alouii Ex-Chef of surgery in Hospital of Sidi Bouzid for his assistance and encouragement to realize this work.

\section{References}

[1] X. Formiguera and A. Cantón, "Obesity: epidemiology and clinical aspects," Best Practice and Research, vol. 18, no. 6, pp. 1125-1146, 2004.

[2] D. W. Haslam and W. P. T. James, "Obesity," The Lancet, vol. 366, no. 9492, pp. 1197-1209, 2005.

[3] M. L. Power and J. Schulkin, "Sex differences in fat storage, fat metabolism, and the health risks from obesity: possible evolutionary origins," British Journal of Nutrition, vol. 99, no. 5, pp. 931-940, 2008. 
[4] S. M. Grundy, "Obesity, metabolic syndrome, and cardiovascular disease," Journal of Clinical Endocrinology and Metabolism, vol. 89, no. 6, pp. 2595-2600, 2004.

[5] P. Singla, A. Bardoloi, and A. A. Parkash, "Metabolic effects of obesity," A Review World Journal of Diabetes, vol. 1, no. 3, pp. 76-88, 2010.

[6] L. A. Profenno, A. P. Porsteinsson, and S. V. Faraone, "Metaanalysis of Alzheimer's disease risk with obesity, diabetes, and related disorders," Biological Psychiatry, vol. 67, no. 6, pp. 505$512,2010$.

[7] C. J. Lavie, R. V. Milani, and H. O. Ventura, "Obesity and cardiovascular disease. risk factor, paradox, and impact of weight loss," Journal of the American College of Cardiology, vol. 53, no. 21, pp. 1925-1932, 2009.

[8] S. Yusuf, S. Reddy, S. Ôunpuu, and S. Anand, "Global burden of cardiovascular diseases. Part I: general considerations, the epidemiologic transition, risk factors, and impact of urbanization," Circulation, vol. 104, no. 22, pp. 2746-2753, 2001.

[9] G. Anfossi, P. Massucco, K. Bonomo, and M. Trovati, "Prescription of statins to dyslipidemic patients affected by liver diseases: a subtle balance between risks and benefits," Nutrition, Metabolism and Cardiovascular Diseases, vol. 14, no. 4, pp. 215-224, 2004.

[10] B. Rahul, R. B. Birari, and K. K. Bhutani, "Pancreatic lipase inhibitors from natural sources unexplored potential," Drug Discovery Today, vol. 12, no. 19-20, pp. 879-889, 2007.

[11] V. Tackholm, Students Flora of Egypt, Cairo University Press, Cairo, Egypt, 1977.

[12] B. A. Beier, M. W. Chase, and M. Thulin, "Phylogenetic relationships and taxonomy of subfamily Zygophylloideae (Zygophyllaceae) based on molecular and morphological data," Plant Systematics and Evolution, vol. 240, no. 1-4, pp. 11-39, 2003.

[13] H. H. Hassanean, E. K. Desoky, and M. M. A. El-Hamouly, "Quinovic acid glycosides from Zygophyllum album," Phytochemistry, vol. 33, no. 3, pp. 663-666, 1993.

[14] D. Smati, A. Longeon, and M. Guyot, " $3 \beta-(3,4-$ Dihydroxycinnamoyl)-erythrodiol, a cytotoxic constituent of Zygophyllum geslini collected in the Algerian Sahara," Journal of Ethnopharmacology, vol. 95, no. 2-3, pp. 405-407, 2004.

[15] A. M. Y. Moustafa, A. I. Khodhair, F. M. Hammouda, and H. A. Husseiny, "Phytochemical and toxicological studies of Zygophyllum album L.F." Journal of Pharmacology and Toxicology, vol. 2, no. 3, pp. 220-237, 2007.

[16] S. R. Hussein, M. M. Marzouk, L. F. Ibrahim, S. A. Kawashty, and N. A. M. Saleh, "Flavonoids of Zygophyllum album L.f. and Zygophyllum simplex L., (Zygophyllaceae)," Biochemical Systematics and Ecology, vol. 39, no. 4-6, pp. 778-780, 2011.

[17] J. El Ghoul, N. Ghanem-Boughanmi, and M. Ben-Attia, "Biochemical study on the protective effect of ethanolic extract of Zygophyllum album on streptozotocin-induced oxidative stress and toxicity in mice," Biomedicine \& Preventive Nutrition, vol. 1, no. 2, pp. 79-83, 2011.

[18] H. Y. Chen, Y. C. Lin, and C. L. Hsieh, "Evaluation of antioxidant activity of aqueous extract of some selected nutraceutical herbs," Food Chemistry, vol. 104, no. 4, pp. 14181424, 2007.

[19] A. Djeridane, M. Yousfi, B. Nadjemi, D. Boutassouna, P. Stocker, and N. Vidal, "Antioxidant activity of some algerian medicinal plants extracts containing phenolic compounds," Food Chemistry, vol. 97, no. 4, pp. 654-660, 2006.

[20] M. Nakai, Y. Fukui, S. Asami et al., "Inhibitory effects of oolong tea polyphenols on pancreatic lipase in vitro," Journal of Agricultural and Food Chemistry, vol. 53, no. 11, pp. 45934598, 2005.

[21] H. G. Shertzer, S. E. Woods, M. Krishan, M. B. Genter, and K. J. Pearson, "Dietary whey protein lowers the risk for metabolic disease in mice fed a high-fat diet," Journal of Nutrition, vol. 141, no. 4, pp. 582-587, 2011.

[22] D. Medrikova, Z. M. Jilkova, K. Bardova, P. Janovska, M. Rossmeisl, and J. Kopecky, "Sex differences during the course of diet-induced obesity in mice: adipose tissue expandability and glycemic control," International Journal of Obesity, vol. 36, pp. 262-272, 2012.

[23] N. Moussavi, V. Gavino, and O. Receveur, "Could the quality of dietary fat, and not just its quantity, be related to risk of obesity," Obesity, vol. 16, no. 1, pp. 7-15, 2008.

[24] Y. Macotela, J. Boucher, T. T. Tran, and C. R. Kahn, "Sex and depot differences in adipocyte insulin sensitivity and glucose," Diabetes, vol. 58, no. 4, pp. 803-812, 2009.

[25] H. J. Park, J. Y. Cho, M. K. Kim et al., "Anti-obesity effect of Schisandra chinensis in 3T3-L1 cells and high fat diet-induced obese rats," Food Chemistry, vol. 134, no. 1, pp. 227-234, 2012.

[26] R. Birari, V. Javia, and K. K. Bhutani, "Antiobesity and lipid lowering effects of Murraya koenigii (L.) Spreng leaves extracts and mahanimbine on high fat diet induced obese rats," Fitoterapia, vol. 81, no. 8, pp. 1129-1133, 2010.

[27] K. Maiza, V. Hammiche, and R. A. Brac de la Perrière, "Traditional saharian pharmacopoeia," in ISHS Acta Horticulturae, H. Schilcher, J. D. Phillipson, and D. Loew, Eds., p. 332, WOCMAP I-Medicinal and Aromatic Plants Conference, Maastricht, The Netherlands, 1993.

[28] G. J. McDougall and D. Stewart, "The inhibitory effects of berry polyphenols on digestive enzymes," BioFactors, vol. 23, no. 4, pp. 189-195, 2005.

[29] M. Yamamoto, S. Shimura, Y. Itoh, T. Ohsaka, M. Egawa, and S. Inoue, "Anti-obesity effects of lipase inhibitor CT-II, an extract from edible herbs, Nomame Herba, on rats fed a highfat diet," International Journal of Obesity, vol. 24, no. 6, pp. 758-764, 2000.

[30] N. A. M. Saleh and M. N. El-Hadidi, "An approach to the chemosystematics of the zygophyllaceae," Biochemical Systematics and Ecology, vol. 5, no. 2, pp. 121-128, 1977.

[31] A. F. Hofmann and B. Borgström, "The intraluminal phase of fat digestion in man: the lipid content of the micellar and oil phases of intestinal content obtained during fat digestion and absorption," The Journal of Clinical Investigation, vol. 43, pp. 247-257, 1964.

[32] A. Halpern and M. C. Mancini, "Treatment of obesity: an update on anti-obesity medications," Obesity Reviews, vol. 4, no. 1, pp. 25-42, 2003.

[33] G. J. McDougall, N. N. Kulkarni, and D. Stewart, "Berry polyphenols inhibit pancreatic lipase activity in vitro," Food Chemistry, vol. 115, no. 1, pp. 193-199, 2009.

[34] F. Carrière, C. Renou, S. Ransac et al., "Inhibition of gastrointestinal lipolysis by Orlistat during digestion of test meals in healthy volunteers," American Journal of Physiology, vol. 281, no. 1, pp. G16-G28, 2001.

[35] S. Subramaniam, R. Subramaniam, S. Rajapandian, S. Uthrapathi, V. R. Gnanamanickam, and G. P. Dubey, "Antiatherogenic activity of ethanolic fraction of terminalia arjuna bark on hypercholesterolemic rabbits," Evidence-Based Complementary and Alternative Medicine, vol. 2011, Article ID 487916, 8 pages, 2011.

[36] B. Perry, J. Junzeng Zhang, C. Sun, T. Saleh, and Y. Wang, "Liuwei Dihuang lowers bodyweight and improves insulin and 
leptin sensitivity in obese rats," Evidence-Based Complementary and Alternative Medicine, vol. 2012, Article ID 847167, 8 pages, 2012.

[37] J. L. Wang, N. Chinookoswong, S. Scully, M. Qi, and Z. Q. Shi, "Differential effects of leptin in regulation of tissue glucose utilization in vivo," Endocrinology, vol. 140, no. 5, pp. 2117 2124, 1999.

[38] F. Galletti, L. D. Elia, D. De Palma et al., "Hyperleptinemia is associated with hypertension, systemic inflammation and insulin resistance in overweight but not in normal weight men," Nutrition, Metabolism \& Cardiovascular Diseases, vol. 22, no. 3, pp. 300-306, 2012.

[39] P. L. Golden, T. J. Maccagnan, and W. M. Pardridge, "Human blood-brain barrier leptin receptor. Binding and endocytosis in isolated human brain microvessels," Journal of Clinical Investigation, vol. 99, no. 1, pp. 14-18, 1997.

[40] R. V. Considine, M. K. Sinha, M. L. Heiman et al., "Serum immunoreactive-leptin concentrations in normal-weight and obese humans," New England Journal of Medicine, vol. 334, no. 5, pp. 292-295, 1996.

[41] G. H. Lee, R. Proenca, J. M. Montez et al., "Abnormal splicing of the leptin receptor in diabetic mice," Nature, vol. 379, no. 6566, pp. 632-635, 1996.

[42] E. W. Shek, M. W. Brands, and J. E. Hall, "Chronic leptin infusion increases arterial pressure," Hypertension, vol. 31, no. 1, pp. 409-414, 1998.

[43] M. Barton, R. Carmona, J. Ortmann, J. E. Krieger, and T. Traupe, "Obesity-associated activation of angiotensin and endothelin in the cardiovascular system," International Journal of Biochemistry and Cell Biology, vol. 35, no. 6, pp. 826-837, 2003.

[44] K. Masuo, H. Mikami, T. Ogihara, and M. L. Tuck, "Weight reduction and pharmacologic treatment in obese hypertensives," American Journal of Hypertension, vol. 14, no. 6 I, pp. 530-538, 2001.

[45] E. L. Santos, K. de Picoli Souza, E. D. da Silva et al., "Long term treatment with ACE inhibitor enalapril decreases body weight gain and increases life span in rats," Biochemical Pharmacology, vol. 78, no. 8, pp. 951-958, 2009.

[46] F. M. Sacks, W. C. Willett, A. Smith, L. E. Brown, B. Rosner, and T. J. Moore, "Effect on blood pressure of potassium, calcium, and magnesium in women with low habitual intake," Hypertension, vol. 31, no. 1 I, pp. 131-138, 1998.

[47] M. R. Joffres, D. M. Reed, and K. Yano, "Relationship of magnesium intake and other dietary factors to blood pressure: the Honolulu heart study," American Journal of Clinical Nutrition, vol. 45, no. 2, pp. 469-475, 1987. 


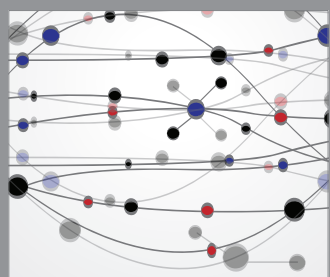

The Scientific World Journal
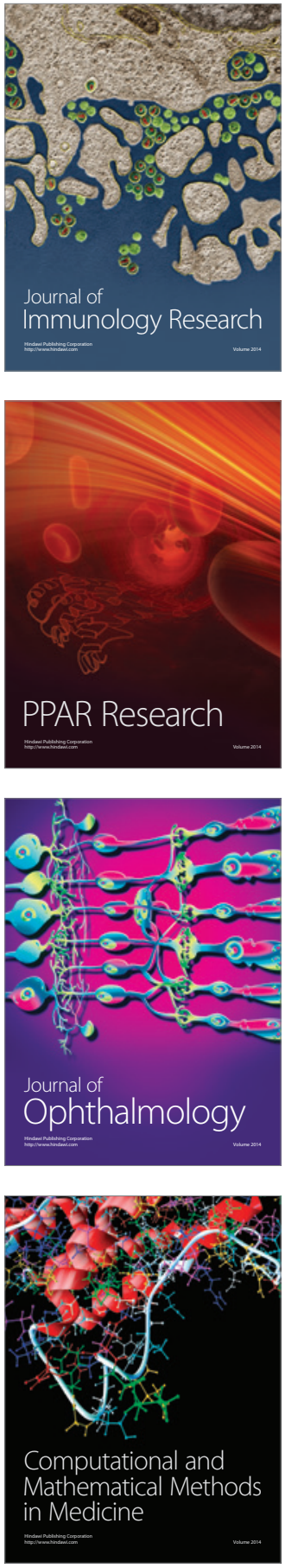

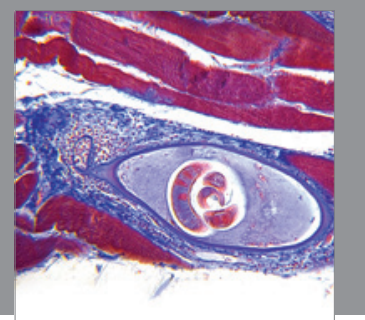

Gastroenterology

Research and Practice
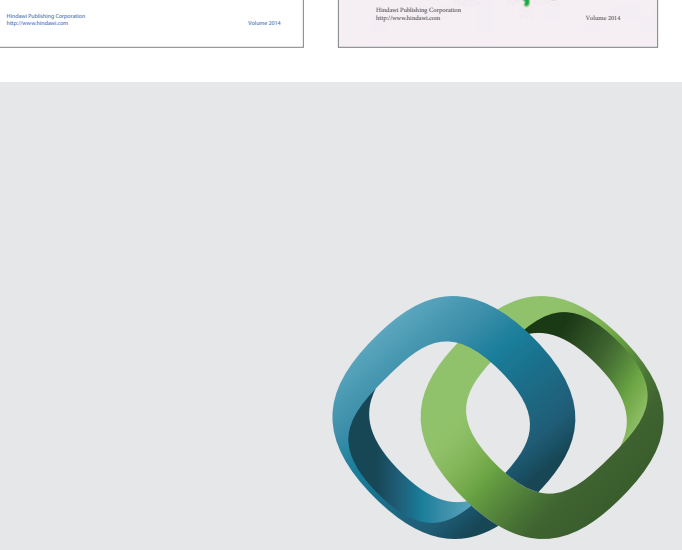

\section{Hindawi}

Submit your manuscripts at

http://www.hindawi.com
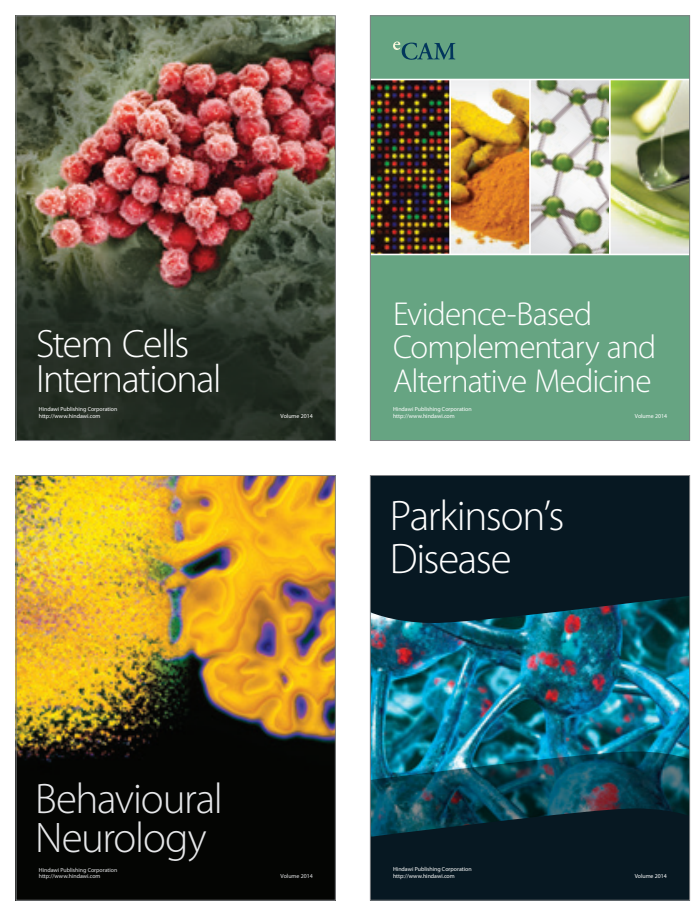

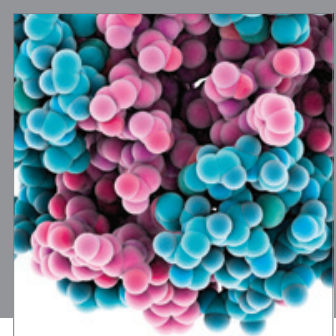

Journal of
Diabetes Research

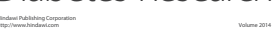

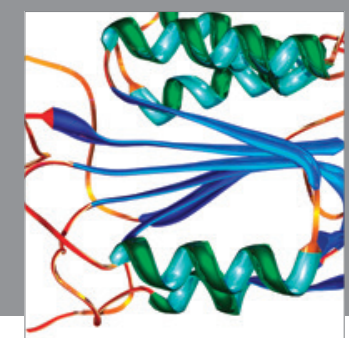

Disease Markers
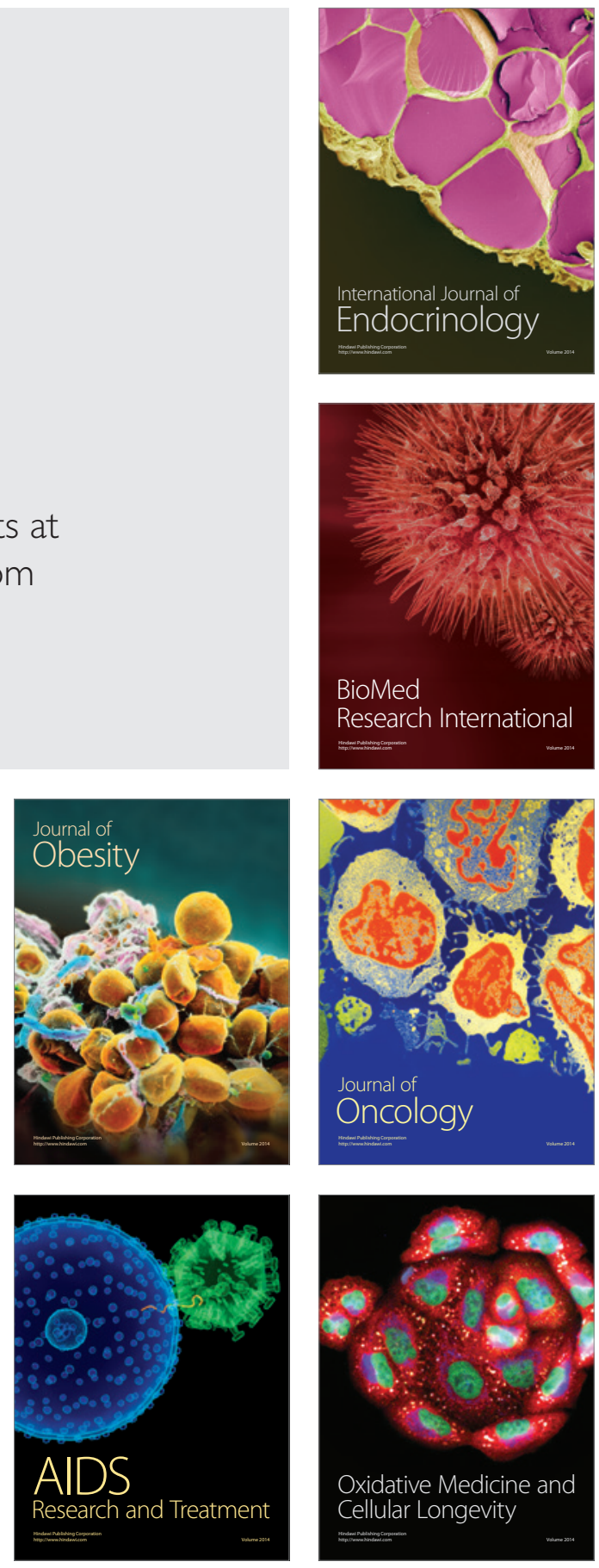